\title{
Prevalence of vitamin D deficiency in pregnancy and its relation with adverse pregnancy outcome
}

\author{
Jyoti Prabha ${ }^{1}$, Abhijeet Kumar ${ }^{2 *}$
}

\begin{abstract}
${ }^{1}$ Department of Obstetrics and Gynecology, Tirath Ram Shah Charitable Hospital, New Delhi, India
${ }^{2}$ Department of Medicine, North Delhi Municipal Corporation and Hindu Rao Hospital, New Delhi, India
\end{abstract}

Received: 23 June 2020

Accepted: 31 July 2020

*Correspondence:

Dr. Abhijeet Kumar,

E-mail: abhijeet978@gmail.com

Copyright: () the author(s), publisher and licensee Medip Academy. This is an open-access article distributed under the terms of the Creative Commons Attribution Non-Commercial License, which permits unrestricted non-commercial use, distribution, and reproduction in any medium, provided the original work is properly cited.

\begin{abstract}
Background: Vitamin D deficiency is widely prevalent in all parts of the world. Pregnant women and neonates are highly vulnerable to vitamin D deficiency. Pregnant women receive very less amount of sunlight especially in parts of Southeast Asia due to traditional norms and customs. A strong positive correlation was found between low maternal vitamin D levels with gestational hypertension/preeclampsia, gestational diabetes mellitus, preterm labour, low birth weight, intra uterine growth restriction, neonatal intensive care unit admission and Apgar score. Therefore, the present study was designed to know the prevalence of vitamin D deficiency in pregnant females and to evaluate adverse effects associated with it.

Methods: Total 250 nulliparous pregnant females attending Tirath Ram Shah Hospital for delivery and carrying a viable ( $>/ 28$ weeks) singleton pregnancy were selected. Women with serum 25 -hydroxy vitamin D level $<10 \mathrm{ng} / \mathrm{ml}$, $10-20 \mathrm{ng} / \mathrm{ml}$ and $<20 \mathrm{ng} / \mathrm{ml}$, were diagnosed as vitamin D deficient, insufficient and sufficient groups respectively and the adverse outcomes was correlated.

Results: In this study, out of 250 cases, 159 cases (63.6\%) had vitamin D deficiency, 43 cases (17.2\%) had insufficiency, and 48 cases $(19.2 \%$ ) had sufficient vitamin D levels (vitamin D $\geq 20 \mathrm{ng} / \mathrm{ml}$ ). And, Vitamin D deficiency was associated with preeclampsia, preterm labour and increased risk of caesarean section.

Conclusions: This study indicates that vitamin D deficiency is highly prevalent in pregnant females thus implicating the need of a uniform strategy of vitamin D supplementation to pregnant females.
\end{abstract}

Keywords: Maternal serum 25 hydroxy vitamin D, Vitamin D deficiency, Vitamin D insufficiency

\section{INTRODUCTION}

Vitamin D status is a well-known determinant of bone health and is related with a risk of many diseases such as cancers, cardiovascular diseases and diabetes. The naturally occurring form of vitamin $\mathrm{D}$ in human beings is cholecalciferol or vitamin D3. Authors receive vitamin D from exposure to sunlight, diet and dietary supplements. The skin synthesis of vitamin D induced by ultra-violet B radiation is the main determinant of vitamin $\mathrm{D}$ status in the population because few food items contain or are fortified with vitamin D. Vitamin D2 or ergocalciferol is derived from plant sterols and is the form contained in most vitamin D supplements.

Vitamin D is a steroid with hormone like activity that regulates the function of over 200 genes and is essential for growth and development of the body. Vitamin D deficiency is widely prevalent in the world. ${ }^{1}$ The South Asian population is at much higher risk due to dark skin pigmentation, limited dietary source of vitamin D and inadequate direct sunlight exposure. However, vitamin D deficiency is being diagnosed increasingly in pregnant woman, infants and children. Indian studies have shown 
the prevalence of vitamin D deficiency in pregnancy to be as high as $84 \%$ in both urban as well as rural areas. ${ }^{2,3}$

Pregnant women, neonates and infants form the most vulnerable group for vitamin D deficiency. Apart from maternal skeletal preservation and fetal skeletal formation it may be linked with other disease susceptibility both in mother as well as fetus. Recent research has suggested that vitamin $\mathrm{D}$ deficiency may put pregnant women at risk for preeclampsia, preterm labour/preterm birth, gestational diabetes and infections, besides poor weight gain and myopathy.

Clinical studies establishing an association between vitamin D level and adverse pregnancy outcomes such as preeclampsia, gestational diabetes, low birth weight, preterm labour, caesarean delivery and infectious diseases have shown conflicting results.

Studies support the idea that lower vitamin D status may play a role in the development of preeclampsia. The active form of vitamin $\mathrm{D}$ (1,25 dihydroxy vitamin $\mathrm{D})$ was proposed to be important for normal placentation, angiogenesis, and immunological tolerance. For example, 1,25 dihydroxy vitamin $\mathrm{D}$ is anti-inflammatory by down regulating the expression of Th1 - type cytokines and upregulating Th-2 type cytokines. ${ }^{4}$

In pregnant women with GDM, pancreatic B cells fail to increase insulin secretion in response to the reduced insulin sensitivity during pregnancy. Both VDR and 1, $\alpha$ hydroxylase are expressed in pancreatic islets. Vitamin D is also known to improve insulin sensitivity by enhancing the expression of insulin receptors. ${ }^{5}$ Vitamin D may reduce the risk of GDM by regulating insulin release and insulin sensitivity.

Vitamin D may be relevant for preterm birth prevention. 1,25-dihydroxyvitamin $\mathrm{D}$ is known to reduce bacterial infections by inducing cathecidin in many tissues, including maternal and fetal cells of the placenta. ${ }^{6}$

Vitamin D has a key role in fetal growth by its interaction with parathyroid hormone and $\mathrm{Ca}+2$ homeostasis. Studies confirmed that insufficient prenatal and postnatal levels of vitamin $\mathrm{D}$ have great effects on bone mineralization which have significant association with small for gestational age (SGA) births. ${ }^{7}$ SGA births are reported more frequent in pregnancies occurring in the winter with vitamin D deficiency.

At present, there are fewer studies to assess the vitamin D status and its relationship with adverse effects in pregnancy in India. So, the objective of this study is to determine the prevalence of vitamin $\mathrm{D}$ deficiency and its relationship with adverse pregnancy outcome. Therefore, current study can be used as a guideline; so that appropriate interventions can be taken to improve the health of these pregnant women and prevent subsequent consequences arising out of vitamin D deficiency and thus helps in future planning and decision making.

\section{METHODS}

This was a prospective comparative study, conducted in the department of obstetrics and gynecology, Tirath Ram Shah hospital, New Delhi, India from $15^{\text {th }}$ June $2017-31^{\text {st }}$ December 2018.

A total 250 nulliparous women who were carrying a viable singleton pregnancy $(>/=28$ weeks) and meeting the inclusion criteria were selected, after obtaining an informed consent in a language understood by the patient.

\section{Inclusion criteria}

Inclusion criteria of this study were women with singleton pregnancy, >/=28 weeks, nulliparous.

\section{Exclusion criteria}

All women with known case of osteomalacia, hyperparathyroidism or hypoparathyroidism, renal dysfunction, liver dysfunction, tuberculosis, sarcoidosis, multiple pregnancy, diabetes mellitus, heart disease, vitamin D supplements, anticonvulsant drugs and rickets.

\section{Procedure}

An approval of the study protocol was obtained from the ethical committee prior to the commencement of the study. 250 nulliparous women carrying a singleton viable pregnancy and meeting the inclusion criteria coming to labour room of TRSCH for delivery were included.

On admission informed consent was taken in all cases. Each patient was subjected to a detailed history (including symptoms of vitamin D deficiency such as generalized body ache, muscular weakness) and thorough clinical examination according to prescribed pro forma. Gestational age was determined using Naegle's formula and confirmed by $1^{\text {st }}$ and $2^{\text {nd }}$ ultrasound if available.

Routine antenatal investigations (haemogram with platelet count, RBS, urine routine and microscopy, HIV, HBSAG and VDRL) and obstetrical USG were taken as evident form patient antennal records.

In all the patient's blood samples for serum 25(OH)D using sandwich ELISA, serum calcium, serum phosphorus, serum parathormone, serum alkaline phosphatase levels were drawn during first stage of labour and subsequently their levels were evaluated.

\section{Vitamin D estimation}

Serum $25(\mathrm{OH})$ D levels were measured by SANDWICH ELISA technique with the help of ELISA kit (immunodiagnostic kit) 
In this study the levels of vitamin $D$ deficiency, insufficiency and sufficiency are taken as

- $\quad$ Vitamin D deficiency $=<10 \mathrm{ng} / \mathrm{ml}$

- Vitamin D insufficiency $=10-20 \mathrm{ng} / \mathrm{ml}$

- $\quad$ Vitamin D sufficiency $=>20 \mathrm{ng} / \mathrm{ml}$.

Other normal ranges of biochemical analysis in third trimester of pregnancy are

- $\quad$ Serum total calcium - 8.2-9.7 mg/dl

- Serum total phosphorus -2.5-4.6 mg/dl

- Serum alkaline phosphatase - 38-229 IU/L

- Serum parathyroid hormone - 9-26 pg/ml.

\section{Statistical analysis}

Categorical variables were presented in number and percentage $(\%)$ and continuous variables were presented as mean \pm SD and median. Normality of data was tested by Kolmogorov-Smirnov test. If the normality was rejected then non parametric test was used. Quantitative variables were compared using ANOVA/Kruskal Wallis test (when the data sets were not normally distributed) between the three groups. Qualitative variables were compared using Chi-Square test. A $p$ value of $<0.05$ was considered statistically significant.

The data was entered in MS excel spreadsheet and analysis was done using statistical package for social sciences (SPSS) version 21.0.

\section{RESULTS}

In this study $19.2 \%, 17.2 \%$ and $63.6 \%$ of participants were lying in normal, insufficiency and deficiency groups respectively.

In this study $37.11 \%, 51.16 \%, 58.33 \%$ of vitamin D deficient, insufficient and sufficient participants were multigravida. $62.89 \%, 48.84 \%$ and $41.67 \%$ of vitamin D deficient, insufficient and sufficient participants were primigravida. So, there was a high distribution of vitamin $\mathrm{D}$ deficiency in both primi- and multi-gravida.
Table 1: Distribution of cases according to vitamin D levels.

\begin{tabular}{|lll|}
\hline Vitamin D levels & Frequency & Percentage \\
\hline Normal & 48 & 19.2 \\
\hline Insufficiency & 43 & 17.2 \\
\hline Deficiency & 159 & 63.6 \\
\hline Total & 250 & 100 \\
\hline
\end{tabular}

A very important correlation was found between vitamin D levels and BMI. This study showed that $16.35 \%$ of vitamin D deficient, $18.60 \%$ of vitamin D insufficient and $8.33 \%$ of sufficient patients belonged to obese category.

The mean maternal calcium levels were relatively lower in the vitamin $D$ deficient group $(8.3 \pm 0.76) \mathrm{mg} / \mathrm{dl}$ compared to vitamin D insufficient group $(8.77 \pm 0.78)$ and sufficient group $(10.96 \pm 12.26)$. The mean maternal phosphorus levels were lower in deficient group $(5.26 \pm 3.09)$ as compared to insufficient $(5.64 \pm 1.81)$ and sufficient group (10.38 \pm 5.74$)$.

S. alkaline phosphatase was raised in $95.60 \%$ of deficient, $88.37 \%$ of insufficient and $89.58 \%$ of sufficient group.

The mean S. PTH level was higher in the Deficient group $(61.64 \pm 48.92)$ as compared to insufficient $(38.99 \pm 18.1)$ and sufficient group $(32.52 \pm 19.15)$.

The proportion of patients with Pre-eclampsia (40.88\%) were more in vitamin D deficient group as compared to insufficient (27.91\%) and sufficient group (6.25\%).

The proportion of patients with pre-term labour in deficient, insufficient, and sufficient groups were $20.75 \%, 20.93 \%$ and $4.17 \%$ respectively.

A total $59.75 \%$ of deficient, $37.21 \%$ of insufficient and $35.42 \%$ of sufficient had LSCS; whereas $40.25 \%$ of deficient, $62.79 \%$ of insufficient and $64.58 \%$ of sufficient group underwent vaginal delivery.

Table 2: Association between BMI and vitamin D level of study participants.

\begin{tabular}{|c|c|c|c|c|c|c|}
\hline & & Vitamin D & & & & \\
\hline & & Deficient (\%) & Insufficient (\%) & Sufficient (\%) & Total & P value \\
\hline & Normal & $66(41.51)$ & 27 (62.79) & 37 (77.08) & $130(52.00)$ & \\
\hline BMI & Overweight & $67(42.14)$ & $8(18.60)$ & $7(14.58)$ & $82(32.80)$ & $<0.0001$ \\
\hline & Obese & $26(16.35)$ & $8(18.60)$ & $4(8.33)$ & $38(15.20)$ & $X^{2}=23.817$ \\
\hline Total & & $159(100.00)$ & $43(100.00)$ & $48(100.00)$ & $250(100.00)$ & $\mathrm{df}=4$ \\
\hline Mean & & $26.18 \pm 3.68$ & $25.37 \pm 3.9$ & $23.78 \pm 3.57$ & $25.58 \pm 3.8$ & \\
\hline
\end{tabular}


Table 3: Levels of S. ALP, S. calcium, S. phosphorus, S. PTH in different group of study participants.

\begin{tabular}{|c|c|c|c|c|}
\hline & Deficient & Insufficient & Sufficient & P value \\
\hline \multicolumn{5}{|l|}{ S.ALP } \\
\hline Sample size & 159 & 43 & 48 & \\
\hline Mean \pm SD & $487.25 \pm 181.76$ & $479.3 \pm 167.62$ & $373.79 \pm 109.31$ & \\
\hline Median & 464 & 464 & 362.5 & 0.0005 \\
\hline Min-max & $171-943$ & $200-730$ & $201-640$ & \\
\hline Inter quartile range & $333-637.500$ & $360-663.250$ & $307.500-430$ & \\
\hline \multicolumn{5}{|l|}{ S. calcium } \\
\hline Sample size & 159 & 43 & 48 & \\
\hline Mean \pm SD & $8.3 \pm 0.76$ & $8.77 \pm 0.78$ & $10.96 \pm 12.26$ & $<0.0001$ \\
\hline Median & 8.4 & 8.9 & 9.1 & \\
\hline Min-Max & $4.1-9.6$ & $5.6-10$ & $8.2-94$ & \\
\hline Inter quartile range & $8-8.800$ & $8.125-9.100$ & $8.850-9.800$ & \\
\hline \multicolumn{5}{|l|}{ S. phosphorus } \\
\hline Sample size & 159 & 43 & 48 & \\
\hline Mean \pm SD & $5.26 \pm 3.09$ & $5.64 \pm 1.81$ & $10.38 \pm 5.74$ & \\
\hline Median & 4.6 & 5 & 9.35 & $<0.0001$ \\
\hline Min Max & $2.2-23$ & $2.8-9.8$ & $3.1-28$ & \\
\hline Inter quartile range & $3.800-5.200$ & $4.200-6.200$ & $7.050-10.650$ & \\
\hline \multicolumn{5}{|l|}{ S.PTH } \\
\hline Sample Size & 159 & 43 & 48 & \\
\hline Mean \pm SD & $61.64 \pm 48.92$ & $38.99 \pm 18.1$ & $32.52 \pm 19.15$ & \\
\hline Median & 48 & 36 & 28 & 0.0002 \\
\hline Min-Max & $6.6-249$ & $4.4-75.7$ & $10-78.7$ & \\
\hline Inter quartile range & $24.850-82$ & $26.175-48.050$ & $17.800-42.400$ & \\
\hline
\end{tabular}

Table 4: Vitamin D levels and associated maternal and fetal complications.

\begin{tabular}{|llll||}
\hline & Vitamin D deficiency (\%) & Vitamin D insufficiency $(\%)$ & Vitamin D sufficiency (\%) \\
\hline Pre-eclampsia & 40.88 & 27.91 & 6.25 \\
\hline LSCS & 59.75 & 37.21 & 35.42 \\
\hline Preterm labour & 20.75 & 20.93 & 4.17 \\
\hline IUGR & 23.90 & 16.28 & \\
\hline
\end{tabular}

LSCS: Lower Segment caesarean section, IUGR: Intra uterine growth restriction.

IUGR was present in $23.90 \%$ of deficient group, $16.28 \%$ of insufficient group and absent in sufficient group.

However, no association was found between vitamin D deficiency and Gestational diabetes mellitus and low birth weight.

\section{DISCUSSION}

In this study, $63.6 \%$ of patients had vitamin D deficiency whereas $17.2 \%$ of patients had vitamin D insufficiency. This study results were similar to the study done by Ravinder et al, South India who found vitamin D deficiency in $67 \%$ of pregnant patients, insufficient in $30 \%$ and sufficient in $3 \% .^{8}$

Mean S. vitamin D level in this study was $11.79 \pm 11.12$. Similar S. vitamin D level was found in the study conducted by Abdurrahman et al (vitamin D level of $14.82 \pm 11.45 \mathrm{ng} / \mathrm{mL}) .{ }^{9}$ Also, in this study the mean value of vitamin D in deficient group is $5.06 \pm 2.17$ which is much lower than in insufficient group (12.8 \pm 2.62$)$ and sufficient group (33.2 \pm 3.34$)$. Similar differences were found in the study conducted by Abdurrahman et al.

In this study the mean age group was 26.68 years with a standard deviation of 4.13 years. The prevalence of vitamin D deficiency was found to be higher in 20-25 age group (44.65\%). A study by Abdurrahman et al, found the prevalence in vitamin D deficiency was higher in 2030 years $(52.6 \%)$.

Majority of primigravida patients in this study i.e., 100 out of $141(70.92 \%)$ were vitamin D deficient. This is in contrast to the study done by Shraddha et al who found slightly higher vitamin D deficiency in multigravida. This 
may be due to the reason that authors are taking only nulliparas in this study. ${ }^{10}$

A very important correlation was found between vitamin D deficiency and increasing BMI in this study. This can be possibly due to the sequestration of vitamin $\mathrm{D}$ in adipose tissue and its lower dietary intake. $16.35 \%$ of vitamin D deficient, $18.60 \%$ of vitamin D insufficient and $8.33 \%$ of sufficient patients belonged to obese category. The difference in between the three groups was found to be of high statistical significance with a p-value of $<0.001$. Bodnar et al concluded in his study that $61 \%$ of women who were obese (BMI >30) before pregnancy were found to be vitamin D deficient as compared to $36 \%$ of women with pre-pregnancy BMI of $<25 .{ }^{11}$

The number of patients with low calcium in deficient, insufficient and sufficient group were $21.38 \%, 25.58 \%$ and $8.33 \%$ respectively. The mean maternal calcium levels were relatively lower in the vitamin $\mathrm{D}$ deficient group $(8.3 \pm 0.76) \mathrm{mg} / \mathrm{dl}$ compared to vitamin $\mathrm{D}$ insufficient group $(8.77 \pm 0.78)$ and sufficient group $(10.96 \pm 12.26)$. This relation was found to be statistically significant (p-value 0.001) and similar to the study conducted by Yasser et al who found a positive linear relationship was found between circulating concentrations of maternal $25(\mathrm{OH}) \mathrm{D} 3$ in pregnancy and serum calcium $(\mathrm{r}=0.81, \mathrm{P}=0.01) .{ }^{12}$ This is in contrast to the study done by Abdurrahman et al who found no significant difference in calcium level in between the three groups.

Low phosphorus was present in $4.40 \%$ of deficient group whereas it is absent in insufficient and sufficient group. However, in this study the mean maternal phosphorus levels were lower in deficient group (5.26 \pm 3.09$)$ as compared to insufficient $(5.64 \pm 1.81)$ and sufficient group $(10.38 \pm 5.74)$. The relation was not found to be statistically significant with a p-value of 0.259. Similar relation was found in the study conducted by Abdurrahman et al and positive correlation was found in Yasser et al study.

The mean maternal alkaline phosphatase levels were higher in the deficient group $(487.25 \pm 181.76)$ as compared to insufficient $(479.3 \pm 167.62)$ and sufficient group (373.79 \pm 109.31$)$. Higher level of alkaline phosphatase was present in $94.97 \%$ of deficient, $88.37 \%$ of insufficient and $100 \%$ of sufficient group. The mean was found to be statistically significant with a p-value of 0.044. Similar, relation was found in the study conducted by Yasser et al and no relation was found in Abdurrahman et al study.

The mean S. PTH level was higher in the deficient group (61.64 \pm 48.92$)$ as compared to insufficient $(38.99 \pm 18.1)$ and sufficient group $(32.52 \pm 19.15)$. S. PTH was raised in $48.43 \%$ of deficient, $74.42 \%$ of insufficient, and $50 \%$ of insufficient patients. This difference was significant with a p-value of 0.004. A study done by Okonofua et al found there was a significant inverse correlation between calcium and PTH, as well as $25(\mathrm{OH}) \mathrm{D}$ and $\mathrm{PTH}$, concentrations. ${ }^{13}$

In this study proportion of patients with Pre-eclampsia $(40.88 \%)$ were more in vitamin D deficient group as compared to insufficient $(27.91 \%)$ and sufficient group $(6.25 \%)$. There was strong association between Preeclampsia and vitamin D level of study participants ( $p-$ value $<0.001$ ). Similar findings were found in Bodner et al. $^{14}$

In the current study the proportion of patients with GDM in vitamin $\mathrm{D}$ deficient, insufficient and sufficient groups were $30.82 \%, 25.58 \%$ and $37.50 \%$ respectively. The association was not found to be statistically significant (p-value 0.465). This association is similar to the study conducted by Farrant et al. ${ }^{15}$ Farrant et al studied 559 pregnant women in India and found no association between second trimester 25(OH)D levels and GDM.

In this study the proportion of patients with pre-term labour in deficient, insufficient, and sufficient groups were $20.75 \%, 20.93 \%$ and $4.17 \%$ respectively. The association was found to be statistically significant with $\mathrm{p}$-value of 0.025 . This association is similar to the study conducted by Bodnar et al. ${ }^{16}$

In this study $59.75 \%$ of deficient, $37.21 \%$ of insufficient and $35.42 \%$ of sufficient had LSCS; whereas $40.25 \%$ of deficient, $62.79 \%$ of insufficient and $64.58 \%$ of sufficient group underwent vaginal delivery. This difference was found to be of statistically significant with p-value of 0.002 . This study is similar to the study conducted by Merewood et al and Scholl et al. ${ }^{17,18}$

IUGR was present in $23.90 \%$ of deficient group, $16.28 \%$ of insufficient group and absent in sufficient group. The association was statistically significant with a p-value of 0.0008. Similar association was found in the studies conducted by Khalessi et al who found that mothers with vitamin $\mathrm{D}$ deficiency gave birth to neonates with head circumference $<33 \mathrm{~cm} .{ }^{19}$ On the other hand Hashemipour et al showed an independent correlation between neonatal head circumference with maternal vitamin D level. ${ }^{20}$

\section{CONCLUSION}

From the above study it can be concluded that vitamin D deficiency is highly prevalent in our country. Pregnant women and neonates are at a higher risk. Pregnant women receive very less amount of sunlight particularly in parts of Southeast Asia due to traditional norms and customs. Vitamin D level above $10 \mathrm{ng} / \mathrm{L}$ is found to have a protective effect against the development of PTL as well as GHTN/ PE. Also, a strong positive correlation was found between maternal vitamin D levels with preterm labour and IUGR. Vitamin D deficiency is a common under diagnosed condition that has received increasing attention in the world. The US Endocrine 
Society guidelines and the IOM recommend screening only in populations at risk, as no evidence currently exists to support screening at a population level.

As calcium demand increases during pregnancy, vitamin D status becomes crucial for optimal maternal and fetal outcome. The high prevalence of vitamin D deficiency in pregnancy calls for unanimous approach to tackle this grave situation by implementing a national strategy for screening, prevention, and treatment of this deficiency. Programs need to be developed to increase the awareness of this problem among people and to provide adequate doses of vitamin D supplements to pregnant females to avoid maternal and fetal complications which may occur due to vitamin D deficiency.

There is a similar gap in the knowledge base for optimal dosing, as there is little empirical robust evidence to support 600 IU/day. Further research is required, particularly to establish the dose needed to supplement pregnant women with pre-existing deficiency and the optimal gestation at which vitamin D supplementation should be started.

\section{Funding: No funding sources}

Conflict of interest: None declared

Ethical approval: The study was approved by the Institutional Ethics Committee

\section{REFERENCES}

1. Mithal A, Wahl DA, Bomjour JP. Global vitamin D status and determinants of hypovitaminosis D. Osteoporos Int. 2009;20:1807-20.

2. Balasubramanian K, Rajeshwari J, Gulab, Govil YC, Agarwal AK, Kumar A. Varying role of vitamin D deficiency in rural girls and pregnant women despite abundant sunshine in northern India. Clin Endocrine. 2009;70:680-4.

3. Sahu M, Bhatia V, Agarwal A, Rawat V, Saxena P, Pandey A. Vitamin D deficiency in rural girls and pregnant women despite adequate sunshine in northern India. Clin Endocrino. 2009;680-684.

4. Diaz L, Noyola-Martinez N, Barrera D, Hernandez G, Avila E, Halhali A, et al. Calcitriol inhibits TNF-alphainduced inflammatory cytokines in human trophoblasts. J ReprodImmunol. 2009;81(1):17-24.

5. Teegarden D, Donkin SS. Vitamin D: emerging new roles in insulin sensitivity. Nutr Res Rev. 2009;22(1):82-92.

6. Hewison M. Antibacterial effects of vitamin D. Nat Rev Endocrinol. 2011;7(6):337-45.

7. Karim S, Nusrat U, Aziz S. Vitamin D deficiency in pregnant women and their newborns as seen at a tertiary - care center in Karachi, Pakistan. Int J Gynaecol Obstet. 2011;112:59-62.
8. Ravinder SS, Deepika C, Padmavathi R, Balakrishnan $\mathrm{K}$, Vijayaraghavan J. Occurrence of vitamin D deficiency in pregnant women in South India - a preliminary study. Int J Pure Appl Biosci. 2015;3:2916.

9. Özdemir AA, Ercan Gündemir Y, Küçük M. Vitamin D deficiency in pregnant women and their infants. J Clin Res Pediatr Endocrinol. 2018;10(1):44-50. doi:10.4274/jcrpe.4706F.

10. Agarwal S, Chaudhary $M$, Chauhan J, Vacchani A. Assessment of Vitamin D Deficiency in Pregnant Females Attending Antenatal Care Clinic at Tertiary Care Hospital. Int J Sci Stud 2016;4(5):99-101.

11. Bodnar LM, Catov JM, Roberts JM, Simhan HN. Prepregnancy obesity pedicts poor vitamin D status in mothers and their neonates. J Nutr. 2007;137:2437-42.

12. Aly, Koumi Y, El Rahman MNA, Rehab. Impact of maternal vitamin $\mathrm{D}$ status during pregnancy on the prevalence of neonatal vitamin D deficiency. Pediatric Reports. 2013;5:10.4081/4616.

13. Okonofua F, Menon RK, Houlder S, Thomas M, Robinson D, O'Brien S, et al. Calcium, vitamin D and parathyroid hormone relationships in pregnant caucasian and asian women and their neonates. Ann Clin Biochem. 1987;24(1):22-8.

14. Bodner LM, Catov JM, Simhan HN, Holick MF, Powers RW, Roberts JM. Maternal vitamin D deficiency increases the risk of preeclampsia. Clin $\mathbf{J}$ Endocrino Metlab. 2007;92:3517-22.

15. Farrant HJ, Krishnaveni GV, Hill JC, Boucher BJ, Fisher DJ, Noonan K, et al. Vitamin D insufficiency is common in Indian mothers but is not associated with gestational diabetes or variation in newborn size. Eur $\mathbf{J}$ Clin Nutr. 2009;63(5):646-52.

16. Bodnar LM, Krohn MA, Simhan HN. Maternal vitamin $\mathrm{D}$ deficiency is associated with bacterial vaginosis in the first trimester of pregnancy. J Nutr. 2009;139(6):1157-61.

17. Merewood A, Mehta SD, Chen TC, Bauchner H, Holick MF. Association between vitamin D deficiency and primary caesarean section. J Clin Endocrinol Metab. 2009;94(3):940-5.

18. Scholl TO, Chen X, Stein P. Maternal vitamin D status and delivery by cesarean. Nutr. 2012;4:319-30.

19. Khalessi N, Kalani M, Araghi M, Farahani Z. The relationship between maternal vitamin $\mathrm{D}$ deficiency and low birth weight neonates. J Family Reprod Health. 2015;9(3):113-7.

20. Hashemipour S, Ziaee A, Javadi A, Movahed F, Elmizadeh K, Javadi EH, et al. Effect of treatment of vitamin D deficiency and insufficiency during pregnancy on fetal growth indices and maternal weight gain: a randomized clinical trial. Eur J Obstet Gynecol Reprod Biol. 2014;172:15-9.

Cite this article as: Prabha J, Kumar A. Prevalence of vitamin D deficiency in pregnancy and its relation with adverse pregnancy outcome. Int J Reprod Contracept Obstet Gynecol 2020;9:3718-23. 